\title{
A PANDEMIA DA COVID-19, A EXPOSIÇÃO DAS DESIGUALDADES E O DISCURSO DA NECROPOLÍTICA NEOLIBERAL.
}

\author{
Carlos Eduardo Cesário Lemos ${ }^{1}$ \\ Universidade Federal Fluminense \\ carlosclemos@gmail.com \\ Guido Cruz de Assis ${ }^{1}$ \\ Universidade Federal Fluminense \\ guidoassis@id.uff.br
}

\section{RESUMO:}

O presente artigo busca evidenciar, a partir do contexto da pandemia da COVID-19, as desigualdades nos acessos ao ciberespaço. Além disso, buscamos problematizar os discursos que evocam o retorno às atividades socioeconômicas que, além de auxiliar na propagação do vírus, ocasionará a morte de milhares de pessoas, exemplificando a necropolítica neoliberal.

Palavras-chave: COVID-19; Desigualdades; Necropolítica Neoliberal.

\section{INTRODUÇÃO}

A pandemia da COVID-19, declarada em 11 de março deste ano, pela Organização Mundial da Saúde (OMS), nos trouxe pautas que precisam ser debatidas com urgência. Desde então, discutia-se sobre o tão questionado isolamento social, medida que já havia sido adotada em diversos países, e acabou impondo novos desafios e questionamentos ao ser implantada no cotidiano brasileiro, como o rearranjo das formas de trabalho e de comunicação. Todavia, mesmo situados num panorama totalmente atípico, os discursos que emanam são de que o ritmo de produção e produtividade não devem ser interrompidos. Logo, explicitaremos não somente as disparidades de acessos ao ciberespaço, mas também analisaremos as narrativas que priorizam a economia e subjugam a vida de milhares de brasileiros.

A partir disso, num primeiro momento, abordaremos os reflexos da medida de isolamento no cotidiano da população brasileira nas dimensões sociocultural e econômica, vislumbrando discutir a ocupação do espaço imaterial e suas contradições em tempos de pandemia. Num segundo momento, buscaremos evidenciar e problematizar os discursos que

\footnotetext{
${ }^{1}$ Graduando de licenciatura em Geografia da Universidade Federal Fluminense - Niterói, RJ - Brasil AO CITAR ESTE TRABALHO, UTILIZE A SEGUINTE REFERÊNCIA:

LEMOS, Carlos Eduardo Cesário; ASSIS, Guido Cruz de. A pandemia da COVID-19, a exposição das desigualdades e o discurso da necropolítica neoliberal. In: Revista Ensaios de Geografia, Niterói, vol. 5, nº 9, p. 34-39, maio de 2020.

Submissão em: 01/05/2020. Aceite em: 23/05/2020.

Universidade Federal Fluminense, Niterói, RJ - Brasil.
} 
são proferidos pelos chefes do poder executivo que pregam a retomada das atividades, servindo a uma política econômica que pode levar à morte milhões de pessoas, sob à luz do conceito de necropolítica neoliberal, desenvolvido por Clara Valverde.

\section{PANDEMIA DA COVID-19: ESPAÇO E POLÍTICAS PÚBLICAS EXCLUDENTES}

De diversas maneiras a pandemia da COVID-19 tem alterado o modo de viver de cada cidadão, com destaque para a adoção da medida de isolamento social, que segundo o professor de medicina de saúde pública da Universidade de Hong Kong, Gabriel Leung (2020), o vírus “pode infectar $60 \%$ da população mundial se não for controlado". Partimos de uma análise sobre a alta mobilidade espacial que, principalmente nos centros urbanos, fora reduzida, impossibilitando que fluxos econômicos-sociais-culturais dessem prosseguimento a sua fluidez e, portanto, afetam diretamente o cotidiano da população em questão - neste caso de pandemia, de grande parte da população mundial. Atividades, serviços básicos, aparelhos de cultura e uma simples conversa entre vizinhos precisaram ser reinventadas, explorando novos espaços geográficos, principalmente o ciberespaço, que Sposito e Guimarães (2020) chamam de "interações espaciais imateriais".

À medida que comércios, indústrias, escolas, universidades, etc. foram fechando ou postergando sua retomada, uma nova forma de experienciar as relações sociais e culturais foi se instaurando. Assim, a "desmaterialização dos processos capitalistas de produção, circulação e consumo" (SILVA, 1999, p. 62) ganha notoriedade e impulso, demarcando seu território nas relações sociais frente à pandemia da COVID-19. Não se trata de negar o espaço geográfico material, seus fluxos, estruturas, sociabilidade presentes nele, mas sim de reconhecer o papel do ciberespaço como uma das únicas ferramentas possíveis para socialização dos indivíduos em um momento como este.

Contudo, é imprescindível apontar que, esse também é um espaço passível de exclusão social. Em 2018, segundo o IBGE, 20,1\% das pessoas residentes em domicílio não possuíam acesso à internet. É interessante ressaltar, que moradores de áreas rurais e/ou periféricas são os mais afetados com a falta de infraestrutura básica e políticas públicas. Além disso, quando trazemos a questão racial para este debate, este índice aumenta. Conforme a Síntese dos Indicadores Sociais sinaliza, "homens e mulheres pretos ou pardos têm restrições em maior proporção, quando comparados a homens e mulheres brancos, para todas as dimensões

AO CITAR ESTE TRABALHO, UTILIZE A SEGUINTE REFERÊNCIA:

LEMOS, Carlos Eduardo Cesário; ASSIS, Guido Cruz de. A pandemia da COVID-19, a exposição das desigualdades e o discurso da necropolítica neoliberal. In: Revista Ensaios de Geografia, Niterói, vol. 5, nº 9, p. 34-39, maio de 2020.

Submissão em: 01/05/2020. Aceite em: 23/05/2020.

Universidade Federal Fluminense, Niterói, RJ - Brasil. 
analisadas. Pretos ou pardos tinham maiores restrições à Internet (23,9\%)" (IBGE, 2019). Assim, comprova-se que as relações de desigualdade extrapolam o espaço real, chegando ao virtual.

Quando se fala em economia, se mantém a desigualdade. Em 2 de abril de 2020, foi publicada a lei 13.982/2020 (BRASIL, 2020, p. 1), conhecida como "lei do auxílio emergencial" que garante a, aproximadamente, 54 milhões de brasileiros, um pagamento no valor de $\mathrm{R} \$ 600$. Para conseguir acesso a esse benefício governamental, é necessário criar uma conta em um aplicativo de celular com acesso à internet, o que já elimina a porcentagem anteriormente citada neste artigo. Ademais, os cidadãos que não podem se cadastrar seja por falta de acesso à internet, ou que não possuem instrução suficiente, ou até mesmo os que foram aprovados segundo critérios da Receita Federal, se aglomeram em filas de banco, a fim de conseguir uma resposta e/ou sacar seu auxílio. Portanto, o Estado põe parte dessa população marginalizada no front do surto, à espera de um milagre, indo contra as recomendações das inúmeras agências sanitárias, nacionais e internacionais, quando "furam" o distanciamento social para garantir o básico à vida. Desse modo, Harvey (2020, p. 14) pontua bem que o "modelo econômico dominante não dá resultados positivos para grande parcela da população".

\section{O DISCURSO DA NECROPOLÍTICA NEOLIBERAL}

Se por um lado parte dos cidadãos de classe média e alta podem rearranjar suas formas de trabalho para dentro de suas casas, outros, por sua vez, precisam estar fisicamente em seus locais de trabalho. É o caso dos porteiros, cozinheiros, cuidadores de idosos, enfermeiros, que precisam se deslocar de suas casas para o trabalho, principalmente por meio do transporte público. É nesse momento que as políticas de Estado deveriam estar baseadas na proteção da população mais pobre e que não tem condições de se adaptar a essa nova realidade que a política de isolamento social impõe. Todavia, os discursos que emanam desde o alto escalão do poder executivo até seus apoiadores da sociedade civil é de que não se deve parar a circulação e os fluxos, ainda que diante de uma crise sanitária totalmente atípica.

A mais recente campanha publicitária do governo de Jair Bolsonaro, cujo o slogan " $\mathrm{O}$ Brasil Não Pode Parar", vai contra as recomendações das principais autoridades sanitárias do mundo e defende o afrouxamento do isolamento social no combate ao avanço do novo 
coronavírus em detrimento da economia. Essa campanha foi interrompida pela Justiça Federal do Rio de Janeiro em caráter temporário (BERTONI, 2020). Não distante do discurso da campanha publicitária do governo brasileiro, no final de fevereiro, o prefeito de Milão, Giuseppe Sala, havia publicado uma campanha cujo o slogan "Milão Não Para" seguia a mesma lógica da campanha exposta anteriormente. Um mês depois, o prefeito afirmou que errou ao disseminar a hashtag que acompanhava o slogan. No início da veiculação da campanha, o número de infectados em Milão era inferior a 300. (CAMPOS, 2020). Atualmente, a Itália chega à trágica estatística de mais de 27 mil mortos, sendo um dos países mais atingidos pela pandemia.

Ambos os discursos dos governantes possuem pontos em comum como a abertura dos comércios, retomada das atividades econômicas e a livre circulação de pessoas. Essas são medidas vistas como prioritárias e que estão acima das vidas que entrarão em contato com a circulação do vírus pelas cidades. A convergência dessas medidas, em direção às diretrizes de Estados e governos neoliberais, favorece a economia e a produção mesmo frente aos precários sistemas públicos de saúde que entrarão em colapso devido aos altos casos de pessoas contaminadas. São essas mesmas diretrizes neoliberais que decretam cortes de verbas para esses sistemas públicos de saúde, não os deixando equiparados e robustos o suficiente para sustentar a demanda de pacientes que aumenta em tempos de pandemia. Portanto, a falta de acesso da população aos serviços de saúde, por meio das políticas de austeridade aplicadas pelos governos neoliberais, além dos discursos que são proferidos, resultará na morte de milhares de cidadãos, como aconteceu na Itália e acontece aqui no Brasil em passos vertiginosos. Afirmar que as pessoas devem abandonar o isolamento social nos exemplifica uma necropolítica, ou seja, uma política da morte.

O conceito de necropolítica, desenvolvido pelo filósofo Achille Mbembe, pode ser definido como "formas contemporâneas que subjugam a vida ao poder da morte" (MBEMBE, 2016, p. 146). A necropolítica neoliberal, por sua vez, termo desenvolvido pela ativista política e social Clara Valverde, não escolhe suas vítimas de forma aleatória. Em entrevista, Valverde (2017) diz que “Os corpos que não são rentáveis para o capitalismo neoliberal, que não produzem nem consomem, são deixados para morrer”. Em outras palavras, os que estão na linha de frente dessa pandemia são aqueles que sempre estiveram às margens da sociedade. As populações mais vulneráveis diante da pandemia, que deveriam ter maior assistência por

AO CITAR ESTE TRABALHO, UTILIZE A SEGUINTE REFERÊNCIA:

LEMOS, Carlos Eduardo Cesário; ASSIS, Guido Cruz de. A pandemia da COVID-19, a exposição das desigualdades e o discurso da necropolítica neoliberal. In: Revista Ensaios de Geografia, Niterói, vol. 5, n 9, p. 34-39, maio de 2020.

Submissão em: 01/05/2020. Aceite em: 23/05/2020.

Universidade Federal Fluminense, Niterói, RJ - Brasil. 
parte do Estado, são as escolhidas para ficarem para trás, pois são as atingidas pelos cortes de verbas e incentivo de privatização dos sistemas de saúde.

\section{CONSIDERAÇÕES FINAIS}

A incompatibilidade das ações governamentais frente à pandemia da COVID-19, seja por meio da falta de oportunidade de acessar o ciberespaço para garantir auxílio emergencial vigente, ou por incentivar o abandono do isolamento social como forma de retomar a produção e priorizar a economia, nos leva a uma política da morte, uma necropolítica neoliberal. As políticas neoliberais que pregam a diminuição do papel do estado na economia e na promoção do bem-estar social, são também políticas de morte por deixarem morrer suas populações através de políticas de austeridade e exclusão (CUTRIN; SEFAIR, 2019). Contudo, esta situação se reverte em tempos de crise, quando o Estado toma para si as consequências econômicas, tentando salvar antes de mais nada o setor empresarial.

A pandemia, em suma, nos faz perceber o quão grave é a situação em que estamos inseridos. Mesmo havendo redes de solidariedade e práticas de resistência, os ataques à sociedade brasileira - com foco na população marginalizada, pobre e negra - já não são mais abafados por discursos assistencialistas.

\section{REFERÊNCIAS BIBLIOGRÁFICAS}

BERTONI, E. O impacto da campanha 'Brasil não pode parar' de Bolsonaro. NEXO JORNAL, [s.1], 27 mar. 2020. Disponível em: <https://www.nexojornal.com.br/expresso/2020/03/27/O-impacto-da-campanha\%E2\%80\%98Brasil-n\%C3\%A3o-pode-parar\%E2\%80\%99-de-Bolsonaro>. Acessado em: 27 abr. 2020.

BRASIL. Lei $n^{\circ} 13.982$, de 2 de abril de 2020. Altera a Lei $\mathbf{n}^{\mathbf{0}} \mathbf{8 . 7 4 2}$, de 7 de dezembro de 1993, para dispor sobre parâmetros adicionais de caracterização da situação de vulnerabilidade social para fins de elegibilidade ao benefício de prestação continuada (BPC), e estabelece medidas excepcionais de proteção social a serem adotadas durante o período de enfrentamento da emergência de saúde pública de importância internacional decorrente do coronavírus (Covid-19) responsável pelo surto de 2019, a que se refere a Lei $\mathbf{n}^{\circ}$ 13.979, de 6 de fevereiro de 2020. Brasília, DF: Diário Oficial da União, p. 1, 2 abr. 2020. Disponível em: <http://www.in.gov.br/en/web/dou/-/lei-n-13.982-de-2-de-abril-de2020-250915958 >. Acessado em: 27 abr. 2020.

CAMPOS, L. H. "Erramos": um mês após campanha para não parar, Milão tem 4,4 mil mortos. CORREIO BRAZILIENSE, [s.1.], 26 mar. 2020. Disponível em: 
<https://www.correiobraziliense.com.br/app/noticia/mundo/2020/03/26/interna_mundo,84054 0/erramos-um-mes-apos-campanha-para-nao-parar-milao-tem-4-4-mil-mort.shtml $>$. Acessado em: 29 abr. 2020.

CUTRIN, I; SEFAIR, C. A necropolítica neoliberal e as políticas de austeridade no governo de Jair Bolsonaro: as reformas, as mulheres e a cidade. PIXO - Revista de Arquitetura, Cidade e Contemporaneidade. vol. 3, n. 10, 2019, p. 30-45.

HARVEY, D. Política anticapitalista em tempos de COVID-19. In: DAVIS, Mike, et al: Coronavírus e a luta de classes. Terra sem Amos: Brasil, 2020, p. 13-24.

IBGE. Síntese de indicadores sociais: uma análise das condições de vida da população brasileira: 2019. IBGE, Coordenação de População e Indicadores Sociais. Rio de Janeiro: IBGE, 2019.

LEUNG, G. Entrevista de Gabriel Leung publicada inicialmente em The Guardian. Reino Unido, 11 de fevereiro de 2020. Disponível em: < https://www.theguardian.com/world/2020/feb/11/coronavirus-expert-warns-infection-couldreach-60-of-worlds-population>. Acessado em: 29 abr. 2020

MBEMBE, A. Necropolíticas. Tradução de Renata Santini. ARTE E ENSAIOS. Rio de Janeiro: n. 32, dez. 2006, p. 128-151.

SILVA, C. A; TANCMAN, M. A dimensão socioespacial do ciberespaço: uma nota. Revista GEOgraphia. vol. 1, n. 2, 1999, p. 55-66.

SPOSITO, M. E; GUIMARÃES, R. Por que a circulação de pessoas tem peso na difusão da pandemia. UNESP, São Paulo: 26 mar. 2020. Disponível em:<https://www2.unesp.br/portal\#!/noticia/35626/por-que-a-circulacao-de-pessoas-tempeso-na-difusao-da-pandemia>. Acessado em: 27 abr. 2020.

VALVERDE, C. Entrevista de Clara Valverde publicada inicialmente em El Diário. Espanha, 11 de julho de 2017. Traduzido por Luiz Morando. Disponível em: <https://resistaorp.blog/2019/04/23/o-neoliberalismo-aplica-a-necropolitica-deixa-morrerpessoas-que-nao-sao-rentaveis>. Acessado em: 28 abr. 2020.

AO CITAR ESTE TRABALHO, UTILIZE A SEGUINTE REFERÊNCIA:

LEMOS, Carlos Eduardo Cesário; ASSIS, Guido Cruz de. A pandemia da COVID-19, a exposição das desigualdades e o discurso da necropolítica neoliberal. In: Revista Ensaios de Geografia, Niterói, vol. 5, nº 9, p. 34-39, maio de 2020.

Submissão em: 01/05/2020. Aceite em: 23/05/2020.

Universidade Federal Fluminense, Niterói, RJ - Brasil. 